Cite this: Phys. Chem. Chem. Phys., 2013,

\title{
An electrochemical impedance study of the oxygen evolution reaction at hydrous iron oxide in base $\dagger$
}

15, 5224

\author{
Richard L. Doyle* and Michael E. G. Lyons
}

Received 1st October 2012,

Accepted 7th January 2013

DOI: $10.1039 / \mathrm{c} 3 \mathrm{cp} 43464 \mathrm{~h}$

www.rsc.org/pccp

\begin{abstract}
The oxygen evolution reaction at multi-cycled iron oxy-hydroxide films in aqueous alkaline solution is discussed. Steady-state Tafel plot analysis and electrochemical impedance spectroscopy have been used to elucidate the kinetics and mechanism of oxygen evolution. Tafel slopes of ca. $60 \mathrm{mV} \mathrm{dec}^{-1}$ and $40 \mathrm{mV} \mathrm{dec}{ }^{-1}$ are found at low overpotentials depending on the oxide growth conditions, with an apparent Tafel slope of ca. $120 \mathrm{mV} \mathrm{dec}{ }^{-1}$ at high overpotentials. Reaction orders of ca. 0.5 and 1.0 are observed at low and high overpotentials, again depending on the oxide growth conditions. A mechanistic scheme involving the active participation of octahedrally coordinated anionic iron oxyhydroxide surfaquo complexes, which form the porous hydrous layer, is proposed. The latter structure contains considerable quantities of water molecules which facilitate hydroxide ion discharge at the metal site during active oxygen evolution. This work brings together current research in heterogeneous electrocatalysis and homogeneous molecular catalysis for water oxidation.
\end{abstract}

\section{Introduction}

Alkaline water electrolysis has been proposed as an environmentally inoffensive route to the production of the large volumes of hydrogen gas required by a possible hydrogen economy. ${ }^{1-5}$ In practice, the efficiency of water electrolysis is limited by the large anodic overpotential of the oxygen evolution reaction (OER). ${ }^{5}$ Over the past thirty years considerable research effort has been devoted to the design, synthesis and characterisation of OER anode materials, with the aim of achieving useful rates of active oxygen evolution at the lowest possible overpotential, thereby optimising the overall electrolysis process. Currently, the optimal OER anode materials are $\mathrm{RuO}_{2}$ and $\mathrm{IrO}_{2}$ since these oxides exhibit the lowest overpotentials for the OER at practical current densities. ${ }^{6}$ However, the high cost of these materials and their poor long term stability in alkaline solution renders their widespread commercial utilisation both uneconomical and impractical. ${ }^{7}$ Considering these limitations, the oxides of the first row transition metals offer a compromise solution. Although they possess inferior electrocatalytic activity for the OER, their relatively low cost and long

Trinity Electrochemical Energy Conversion \& Electrocatalysis (TEECE) Group, School of Chemistry and CRANN, University of Dublin Trinity College, Dublin 2, Ireland. E-mail: rdoyle5@tcd.ie, melyons@tcd.ie; Fax: +353 (0)1671 2826; Tel: $+353(0) 18962032$

$\dagger$ This publication is based on a presentation given as part of the Fundamental Electrochemistry Symposium at Electrochem 2012 in Dublin, Ireland. term corrosion resistance in alkaline solution makes them attractive OER anode materials. ${ }^{7-12}$

At present, a significant body of research exists on the application of non-noble transition metal oxides as OER anodes. Amongst the most promising materials are various intermetallic alloys ${ }^{13}$ electrodeposited nickel, ${ }^{14}$ cobalt ${ }^{15}$ and manganese oxides, ${ }^{16}$ spinels including nickelites, ${ }^{17}$ cobaltites ${ }^{18}$ and ferrites, ${ }^{19}$ perovskites, ${ }^{20}$ and hematite photoanodes. ${ }^{21}$ However, despite these intense efforts the mechanism of the OER at first row transition metal oxide surfaces remains controversial and the important question of a common mechanism which would facilitate a theory of electrocatalysis for oxygen evolution is therefore unresolved. It is our opinion that a systematic and consistent study of the OER at the oxidised surfaces of adjacent first row transition metals should prove useful in elucidating whether a common reaction mechanism prevails.

In terms of a mechanistic analysis of the OER, the major difficulty lies in the fact that the OER is a complex process involving the transfer of 4 electrons. In alkaline solution, the overall half-cell reaction may be represented as,

$$
4 \mathrm{OH}^{-} \rightarrow \mathrm{O}_{2}+2 \mathrm{H}_{2} \mathrm{O}+4 e^{-}
$$

Consequently, the OER may follow any of a number of different pathways. Various possible mechanistic schemes have been proposed over the years with notable early studies including the works of Bockris, ${ }^{20 a}$ Krasil'shchikov, ${ }^{22}$ Kobussen $^{23}$ and O'Grady. ${ }^{24}$ Interestingly, these early mechanistic schemes share 
a common feature in that the initial catalytic step involves the discharge of a hydroxide ion at a catalytically active surface site $\mathrm{S}$ to form a surface adsorbed hydroxide $\mathrm{SOH}$,

$$
\mathrm{S}+\mathrm{OH}^{-} \rightarrow \mathrm{SOH}+e^{-}
$$

Subsequent steps in the reaction have been attributed to the formation of a range of surface adsorbed intermediates such as $\mathrm{SO}, \mathrm{SOOH}$, or physisorbed peroxide species with the specific details of each step depending on the various anode materials and experimental conditions.

In light of this, much research has been devoted to the determination of rate-determining steps and to the identification of a catalytic activity descriptor for the OER. ${ }^{25}$ Indeed, considering the variety of OER anode materials in the literature the idea of a universal 'descriptor' is particularly attractive. In their seminal electrochemical work, Bockris and Ottagawa ${ }^{20 a}$ suggested that the catalytic OER activity correlated inversely with the surface bond energy of $\mathrm{OH}$. Accordingly, the rate determining step may be the desorption of $\mathrm{OH}$ or oxygenated species from the surface. More recently, theoretical calculations based on Density Functional Theory (DFT) and Molecular Orbital (MO) Theory have made significant contributions to the study of the OER. Rossmeisl et al. ${ }^{26}$ suggest that the surface oxygen binding energy is a suitable descriptor for OER activity with the formation of a surface adsorbed ${ }^{*} \mathrm{OOH}$ species being rate-determining at rutile-type oxides such as $\mathrm{RuO}_{2}, \mathrm{IrO}_{2}$ and $\mathrm{TiO}_{2}$. On the other hand, Suntivich et al. ${ }^{27}$ and Subbaraman et $a .^{28}$ have focused their catalytic analysis at a more atomic/ molecular scale. The former authors argue that the level of occupancy of the $\mathrm{e}_{\mathrm{g}}$-symmetry electrons in the transition metal $\mathrm{M}$ of a perovskite $\mathrm{AMO}_{3}$ is a suitable descriptor as it determines the binding of oxygen intermediates to the metal $\mathbf{M}$ whereas, the latter authors propose a correlation between the metalhydroxide bond strength in 3d-metal oxyhydroxide surface clusters and their OER catalytic activity.

In recent years, molecular catalysts for water oxidation have also received considerable research attention. ${ }^{29}$ One of the advantages of these systems is the ease with which mechanistic studies can be performed. In this respect, it is interesting to observe that intermediate species similar to those proposed for heterogeneous systems, such as $\mathbf{M}-\mathrm{OH}, \mathbf{M}=\mathrm{O}$ and $\mathrm{M}-\mathrm{OOH}$ where $\mathrm{M}$ is a catalytically active metal centre, are typically implicated for the molecular catalysts. ${ }^{29}$ Indeed, to facilitate a comparison of mechanisms it has been noted that the discharge of a hydroxide ion at an electrode surface, such as that outlined in eqn (2), can be related to ligation of the hydroxide ion to a metal of the surface oxide, with a resultant increase of one in the formal oxidation state of the metal. ${ }^{25 a}$ Moreover, it has been suggested that bulk metal oxides represent a catalytic material which may share properties with both heterogeneous electrocatalysts and homogeneous molecular catalysts. In their informative review, Dau et al. ${ }^{25 a}$ pose the tantalising conceptual question of whether the more amorphous metal oxide/hydroxide materials can be viewed best as an extended solid-state material or rather an aggregate of multiple metal oxide complexes with molecular properties. Certainly, these concepts are of particular relevance to our current research.

In the present work, we focus on the oxygen evolution electrocatalytic properties of polymeric iron oxyhydroxide electrodes in alkaline solution. Here, we examine the OER kinetics using a combination of steady state polarization techniques, reaction order studies and electrochemical impedance spectroscopy (EIS). Based on the available kinetic data, we propose a mechanism for the OER which specifically takes into account the nature of the electrochemically generated hydrous iron oxide film present on the surface of the iron electrode during active oxygen evolution. In particular, we intend to highlight the potential benefits of drawing on current thinking in both heterogeneous and homogeneous OER catalysis.

\section{Experimental}

All experiments were conducted in a conventional three electrode cell. The working electrode was constructed from $1.0 \mathrm{~mm}$ thick polycrystalline iron foil (as supplied by Alfa Aesar-Johnson Matthey, purity $99.9945 \%$ (metals basis)) with a geometric surface area of $0.16 \mathrm{~cm}^{2}$. Prior to each experiment the surface of the working electrode was polished successively with 1200 grit carbimet paper and a slurry of $0.3 \mu \mathrm{m}$ alumina powder until a "mirror bright" finish was achieved. A platinum wire electrode (CH Instruments, cat no. CHI 115) was employed as the counter electrode and a mercury-mercuric oxide $(\mathrm{Hg} / \mathrm{HgO})$ reference electrode ( $\mathrm{CH}$ Instruments, cat no. $\mathrm{CHI} 152$ ) was utilised as the reference standard, therefore all voltages are quoted against this reference electrode. The various electrolyte solutions were prepared from sodium hydroxide pellets (SigmaAldrich, minimum $99.0 \%$ purity), boric acid (BDH, minimum 99.5\% purity) and sodium sulphate (Sigma-Aldrich, minimum 99.0\% purity) using Millipore water (resistivity >15 $\mathrm{M} \Omega \mathrm{cm}$ ). Aqueous sodium hydroxide solutions served as both the electropolymerization medium and the primary supporting electrolyte for the redox switching and electrocatalytic studies. Borate buffer solutions acted as the supporting electrolyte for the $\mathrm{pH}$ experiments. These solutions contained $0.25 \mathrm{~mol} \mathrm{dm}^{-3}$ boric acid and were made up to the appropriate $\mathrm{pH}$ using a $5.0 \mathrm{~mol} \mathrm{dm}{ }^{-3} \mathrm{NaOH}$ solution. The ionic strength of each buffer solution was fixed at ca. $3.0 \mathrm{~mol} \mathrm{dm} \mathrm{dm}^{-3}$ using $1.0 \mathrm{~mol} \mathrm{dm}^{-3}$ $\mathrm{Na}_{2} \mathrm{SO}_{4}$. Before commencing each experiment, nitrogen gas was bubbled through the electrolyte solution for $20 \mathrm{~min}$.

The electrochemical measurements, with the exception of the impedance measurements, were performed using a range of high performance potentiostats including a CHI760D bipotentiostat, an Autolab PGSTAT302N potentiostat/galvanostat, and Gamry Reference 3000 and 600 potentiostat/galvanostat/ZRA systems. Unless otherwise specified, all values of current density are normalized with respect to the geometric surface area of the electrode. Tafel plots were recorded using linear sweep voltammetry which was performed at a sweep rate of $1 \mathrm{mV} \mathrm{s}^{-1}$ in the positive direction. Each Tafel plot was corrected for $i R$ drop. Accordingly, the uncompensated solution resistance was determined using chronoamperometry. The current 
response to a small potential step $(50 \mathrm{mV})$ was recorded in a potential region where no Faradaic processes were occurring. The solution resistance was then calculated using the relationship,

$$
i=\frac{\Delta E}{R} \exp \left(\frac{-t}{R_{\mathrm{u}} C_{\mathrm{dl}}}\right)
$$

where $\Delta E$ is the magnitude of the potential step $(\mathrm{V}), R_{\mathrm{u}}$ is the solution resistance ( $c a .4 .0 \Omega$ for $\left.1.0 \mathrm{~mol} \mathrm{dm}^{-3} \mathrm{NaOH}\right), t$ is time (s) and $C_{\mathrm{dl}}$ is the double layer capacitance (ca. $47 \mu \mathrm{F} \mathrm{cm} \mathrm{cm}^{-2}$ for a 120 cycled hydrous oxide film). Electrochemical impedance spectroscopy was performed using a Zahner Elektrik IM6 electrochemical measurement unit. The impedance spectra were recorded by employing a $10 \mathrm{mV}$ peak to peak amplitude sine wave potential perturbation on the dc potential. The dc potential was changed step wise in the positive direction, with sufficiently long delays to achieve steady state conditions. This has been checked by applying Kramers-Kronig tests to the measured spectra. Complex non-linear least squares (CNLS) fitting of raw impedance data to equivalent circuit models was conducted using the SIM module of the IM6 Thales software suite. Initial estimates for the capacitive and resistive circuit elements were obtained from the Bode plots using a built in parameter estimate function. These estimates were then used as seed values for the CNLS fitting procedure. To check the fitting results selected experimental data was also fitted using the Autolab NOVA software package (version 1.8). In this procedure RC initial estimates were obtained using a circle fitting function. Similar fitting parameters were obtained using both software packages.

Scanning electron microscopy (SEM) was performed using a Zeiss Ultra Plus equipped with a high resolution $(<1 \mathrm{~nm})$ field emission SEM and a Gemini ${ }^{\circledR}$ column.

The polymeric iron oxyhydroxide films were prepared by multi-cycling a polycrystalline iron electrode in the requisite electrolyte solution between appropriate switching potentials. The aforementioned experimental parameters have been varied in this work and so the pertinent values are noted in the relevant results sections. Films of different thicknesses were prepared by varying the number of growth cycles in the multicycling procedure. The charge storage capacity or redox capacity $(Q)$ was determined following the growth of each film by integrating the peaks in a voltammetric profile recorded at a slow sweep rate $\left(40 \mathrm{mV} \mathrm{s}^{-1}\right)$. The redox capacity is directly proportional to the thickness of the layer.

\section{Results and discussion}

\section{Preparation and voltammetry of hydrous iron oxides}

Cyclic voltammograms recorded for typical hydrous oxide layers prepared using different numbers of growth cycles are presented in Fig. 1. The surface redox chemistry and the factors affecting the growth of hydrous iron oxides in base have been discussed in detail by Lyons and coworkers ${ }^{11,30}$ and thus we offer only a brief outline here. It is clear from Fig. 1 that only peak A3 and its cathodic complement C2 increase in charge magnitude with repetitive potential cycling. This observation,

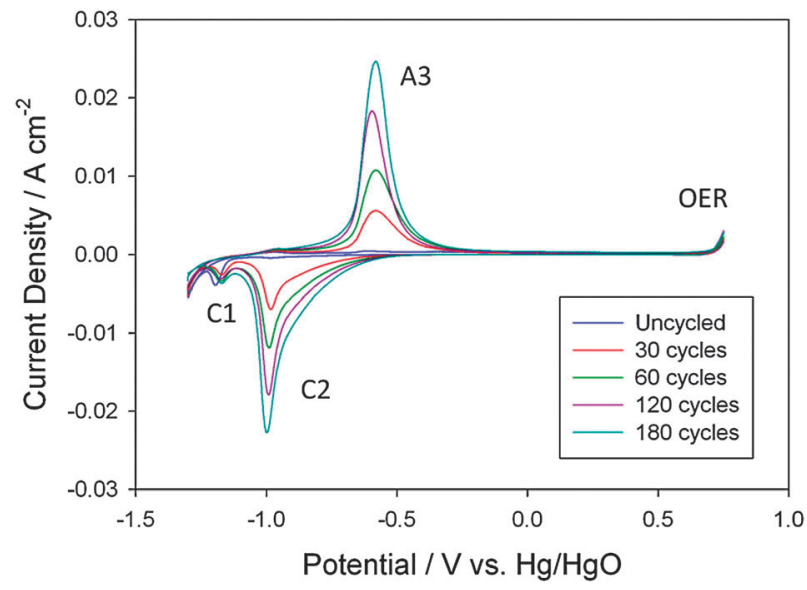

Fig. 1 Cyclic voltammograms recorded in $1.0 \mathrm{M} \mathrm{NaOH}$ at a sweep rate of $40 \mathrm{mV} \mathrm{s}^{-1}$ for hydrous iron oxide films prepared using a range of growth cycles. The films were grown in $0.5 \mathrm{M} \mathrm{NaOH}$ between switching potentials of $-1.30 \mathrm{~V}$ and $0.75 \mathrm{~V}$ at a sweep rate of $400 \mathrm{mV} \mathrm{s}^{-1}$.

in tandem with the fact that these peaks exhibit a supernernstian $E$-pH dependence, typically in the region of 88-100 $\mathrm{mV}$ per $\mathrm{pH}$ unit at $25{ }^{\circ} \mathrm{C}$, is suggestive of an $\mathrm{Fe}(\mathrm{II}) / \mathrm{Fe}$ (III) redox transition in an outer hydrated and dispersed region of the oxide. ${ }^{31}$

This concept of a hydrated outer oxide layer is well established. Early ellipsometric and spectroscopic studies performed by Bockris ${ }^{32}$ and O'Grady ${ }^{33}$ pointed to the presence of bound water in the passive layer formed on polycrystalline iron. In particular, these authors suggested a hydrated polymeric oxide model for the passive oxide layer. In terms of the electrochemically generated hydrous oxide films prepared in the current work, the oxide/solution interface is thought to consist of an inner compact anhydrous layer $\mathrm{MO}_{x}$ and an outer microdispersed hydrous layer of general form $\mathrm{MO}_{a}(\mathrm{OH})_{b}\left(\mathrm{OH}_{2}\right)_{c}$. This is the duplex layer model proposed by Burke and coworkers ${ }^{34}$ and depicted graphically in Fig. 2a. Accordingly, $\left[\mathrm{Fe}_{2} \mathrm{O}_{3}(\mathrm{OH})_{3}\left(\mathrm{OH}_{2}\right)_{3}\right]^{3-}$ has been proposed as a formula for the repeating unit of the outer $\mathrm{Fe}(\mathrm{III})$ based oxide product with charge neutrality maintained by associated counter-ions. On repetitive cycling, this porous outer layer increases in thickness at the expense of the underlying metal. Certainly, the oxide layers prepared in this manner exhibit significant surface roughness as can be observed clearly from the SEM micrograph presented in Fig. 2b.
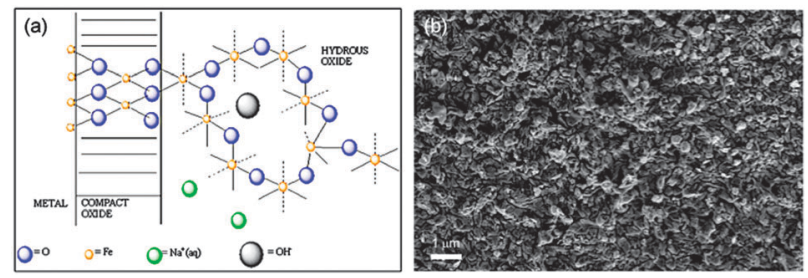

Fig. 2 (a) Schematic representation of the Burke-O'Sullivan Duplex Layer Model of the oxide/solution interface. (b) SEM image of a hydrous oxide covered iron electrode. The film was prepared in $1.0 \mathrm{M} \mathrm{NaOH}$ for 120 cycles between $-1.30 \mathrm{~V}$ and $0.75 \mathrm{~V}$ at a sweep rate of $400 \mathrm{mV} \mathrm{s}^{-1}$. 


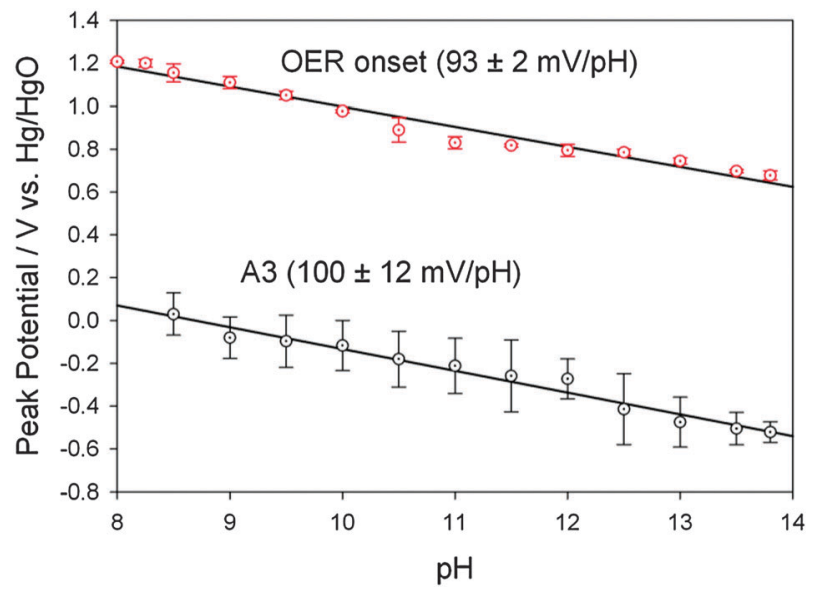

Fig. 3 The A3 peak potential and the OER onset potential for a typical hydrous iron oxide covered electrode plotted as a function of the solution $\mathrm{pH}$. Error bars representing $2 \sigma$ are also shown.

It has been noted that dispersed hydrated oxide materials exhibit good electrocatalytic potentiality due to their skeletal nature as the latter structural feature permits a major increase in the number of oxyions participating in the electrode reaction. ${ }^{11,30}$ Indeed, with microdispersed species the boundary between the solid and aqueous phase may be nebulous as the two phases virtually intermingle. This will be an important consideration when a model for the OER is developed. In our mechanistic analysis we specifically implicate the hydrous layer as the catalytic species. This assertion is supported by the $\mathrm{pH}$ dependence of the OER at hydrous iron oxide covered electrodes. In Fig. 3, E-pH plots generated for peak A3 and the OER onset potential are presented for comparison. As stated previously, the redox peaks associated with the hydrous layer exhibit a super-nernstian $E$-pH dependence, here A3 shifts negatively by ca. $0.1 \mathrm{~V}$ per $\mathrm{pH}$ unit. Significantly, the OER onset potential exhibits an $E$-pH shift of similar magnitude to peak A3, $c a$. $-0.093 \mathrm{~V}$ per $\mathrm{pH}$ unit, suggesting that the anionic surfaquo groups of the hydrous layer actively partake in oxygen evolution at hydrous oxide covered iron electrodes.

\section{Steady-state polarisation}

Steady-state polarisation curves were recorded for hydrous oxide films prepared using a range of base concentrations. Typical $i R$ corrected Tafel plots for hydrous oxide films prepared in 0.5 and $1.0 \mathrm{~mol} \mathrm{dm}^{-3} \mathrm{NaOH}$ using increasing numbers of growth cycles are presented in Fig. 4. The important kinetic feature evident in Fig. 4 is the variation in the Tafel characteristic with electropolymerisation solution. Dual Tafel slopes were exhibited by all the hydrous oxide films examined, with a Tafel slope $b c a .120 \mathrm{mV} \mathrm{dec}{ }^{-1}\left(\approx 2.303 \times 2 R T / F\right.$ at $\left.25{ }^{\circ} \mathrm{C}\right)$ uniformly observed at high overpotentials. The continuous increase in Tafel slope observed at even higher overpotentials is likely due to increased bubble formation causing a steady decrease in the effective electrode surface area. However, at low overpotentials the Tafel slope was dependent on the base concentration used to prepare the film. When the
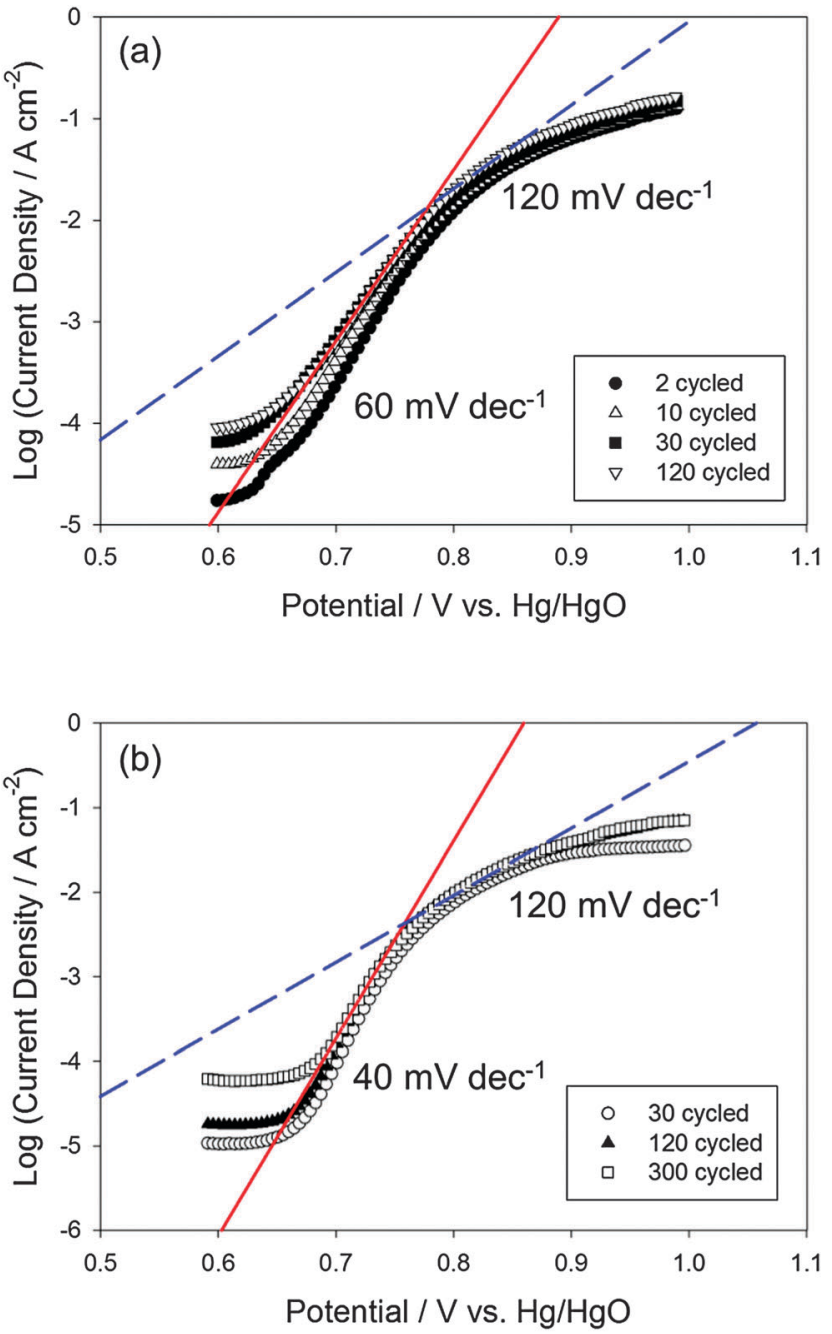

Fig. 4 Steady-state polarisation curves recorded in 1.0 M NaOH for hydrous iron oxide films prepared using a range of growth cycles. The films were grown (a) in $1.0 \mathrm{M} \mathrm{NaOH}$ between switching potentials of $-1.45 \mathrm{~V}$ and $0.35 \mathrm{~V}$ at a sweep rate of $350 \mathrm{mV} \mathrm{s}^{-1}$ and (b) in $0.5 \mathrm{M} \mathrm{NaOH}$ between switching potentials of $-1.30 \mathrm{~V}$ and $0.75 \mathrm{~V}$ at a sweep rate of $400 \mathrm{mV} \mathrm{s}^{-1}$.

concentration of $\mathrm{NaOH}$ was greater than or equal to $1.0 \mathrm{~mol} \mathrm{dm}^{-3} b$ was $c a .60 \mathrm{mV} \mathrm{dec^{-1 }}\left(\approx 2.303 \times R T / F\right.$ at $\left.25{ }^{\circ} \mathrm{C}\right)$ whereas for $\mathrm{NaOH}$ concentrations less than or equal to $0.5 \mathrm{~mol}$ $\mathrm{dm}^{-3}$ the Tafel slope $b$ was $c a .40 \mathrm{mV} \mathrm{dec^{-1 }}(\approx 2.303 \times 2 R T / 3 F$ at $25{ }^{\circ} \mathrm{C}$ ). These two distinct sets of Tafel slopes have been designated Type A and Type B respectively. ${ }^{35}$

The effect of solution $\mathrm{OH}^{-}$ion concentration on the rate and kinetics of the OER at these different hydrous oxide films was also investigated. For each experiment, the oxide layer was grown for the requisite number of cycles in the appropriate electropolymerisation solution and the electrode was then transferred to the test solution. A comparison of the steady state polarisation curves obtained for 120 cycled hydrous oxide films in various base concentrations is presented in Fig. 5. It can be seen from each of the plots in Fig. 5 that the Tafel characteristics for each film remain the same regardless of base concentration, suggesting that the nature of the rate 

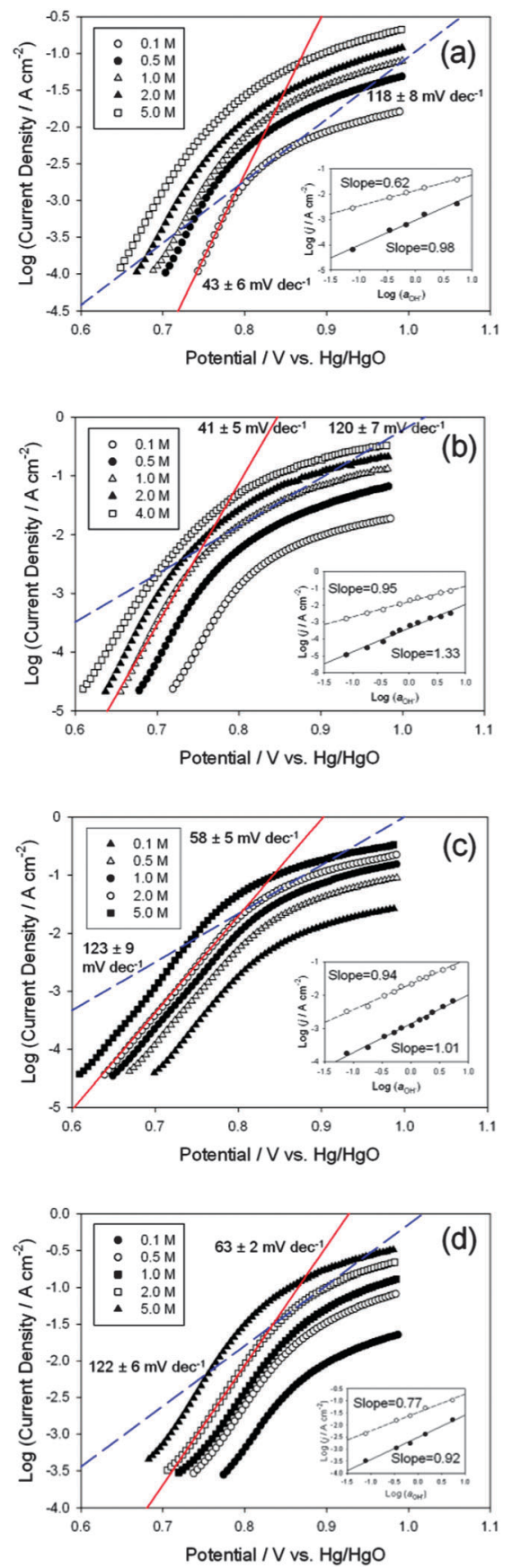

Fig. 5 Steady-state polarisation curves recorded in a series of base concentrations for hydrous iron oxide films prepared using 120 growth cycles. The films were grown (a) in $0.1 \mathrm{M} \mathrm{NaOH}$ between switching potentials of $-1.33 \mathrm{~V}$ and $0.75 \mathrm{~V}$ at a sweep rate of $400 \mathrm{mV} \mathrm{s}^{-1}$, (b) in $0.5 \mathrm{M} \mathrm{NaOH}$ between $-1.30 \mathrm{~V}$ and $0.75 \mathrm{~V}$ at a sweep rate of $400 \mathrm{mV} \mathrm{s}^{-1}$, (c) in $1.0 \mathrm{M} \mathrm{NaOH}$ between $-1.45 \mathrm{~V}$ and $0.35 \mathrm{~V}$ at a sweep rate of $350 \mathrm{mV} \mathrm{s}^{-1}$ and $(\mathrm{d})$ in $5.0 \mathrm{M} \mathrm{NaOH}$ between $-1.38 \mathrm{~V}$ and $0.65 \mathrm{~V}$ at a sweep rate of $400 \mathrm{mV} \mathrm{s}^{-1}$. Reaction order plots generated at fixed potentials in the low and high Tafel slope regions are shown in the insets of each graph.

determining step is unaffected by the concentration of $\mathrm{OH}^{-}$ ions in solution. Again, Tafel slopes of $c a$. 60 and $40 \mathrm{mV} \mathrm{dec}{ }^{-1}$ were observed at lower potentials for Type A and Type B films respectively, with a Tafel slope of approximately $120 \mathrm{mV} \mathrm{dec}-1$ becoming evident at higher overpotentials. Reaction order plots with respect to $\mathrm{OH}^{-}$ion activity (calculated from literature values $^{36}$ for the mean ionic activity coefficients, $\gamma \pm$ ) are constructed in the insets of Fig. 5. As was observed for the Tafel slopes, the reaction orders $\mathrm{mOH}^{-}$were found to be dependent on the electropolymerisation solution. Reaction orders of $0.98 \pm 0.15,1.33 \pm 0.12,1.01 \pm 0.12$ and $0.92 \pm 0.04$ were obtained at potentials located in the low Tafel region for hydrous oxide films prepared in $0.1,0.5,1.0$ and $5.0 \mathrm{~mol} \mathrm{dm}^{-3}$ respectively. In the high Tafel region the corresponding reaction orders were $0.62 \pm 0.05,0.95 \pm 0.18,0.94 \pm 0.06$ and $0.77 \pm 0.10$ respectively. Similar numerical values for the reaction orders were obtained for hydrous oxide layers prepared using a range of growth cycles indicating that the reaction order is not dependent on the hydrous oxide charge capacity.

The results outlined above highlight a clear dependence of the hydrous oxide OER kinetic parameters on the electropolymerisation solution. To explain this phenomenon it is instructive to consider the effect of base concentration on the growth of the hydrous oxide film. The rate of oxide growth is known to decrease with increasing number of growth cycles. Lyons and coworkers ${ }^{11}$ have noted that this decrease can be attributed to the increasing inhibition of water and hydroxide ion transfer to the inner region of the oxide layer with increasing hydrous oxide thickness and that this effect becomes more marked with increasing base concentration. Evidently, increased hydroxide ion activity suppresses hydroxide dissociation and/or favours adsorption of this species thereby inhibiting nucleation and growth of the microdisperse hydrous layer. Indeed only limited development of the hydrous layer can be achieved in very concentrated base, with inhibition of hydrous oxide growth becoming apparent after only 20-30 growth cycles in $5.0 \mathrm{~mol} \mathrm{dm}{ }^{-3} \mathrm{NaOH}$.

In light of this, we propose that the variation in the electrocatalytic properties associated with the hydrous oxide film is ultimately a dehydration or 'aging' effect. The films prepared in the more concentrated base solutions are thought to be more dehydrated than those prepared in the lower base concentrations. Thus, it is the increasingly dehydrated nature of the hydrous oxide films that is responsible for the changing electrocatalytic properties. To further illustrate this idea we investigated the effect of 'aging' on the Tafel characteristics of a hydrous oxide layer. 'Aging' in this sense refers to immersing a freshly prepared hydrous oxide covered electrode in $5.0 \mathrm{~mol} \mathrm{dm}^{-3}$ $\mathrm{NaOH}$ for a prolonged period of time. In Fig. 6 a comparison of the Tafel plots recorded for a Type B hydrous oxide film in $5.0 \mathrm{~mol} \mathrm{dm}^{-3} \mathrm{NaOH}$ before (Fig. 6a) and after (Fig. 6b) 'aging' for 2 hours. The lower Tafel slope was observed to increase from $44 \mathrm{mV} \mathrm{dec}^{-1}$ to $58 \mathrm{mV} \mathrm{dec}{ }^{-1}$ with 'aging'. Dehydrating the layer in strong base effectively transformed it from a Type B hydrous oxide film into one exhibiting Type A behaviour. In this way, we can attribute the variation in the OER kinetic parameters to changes in the level of hydration of the hydrous layer.

\section{Electrochemical impedance spectroscopy}

Electrochemical impedance spectroscopy was employed to obtain a better understanding of the different OER kinetic 

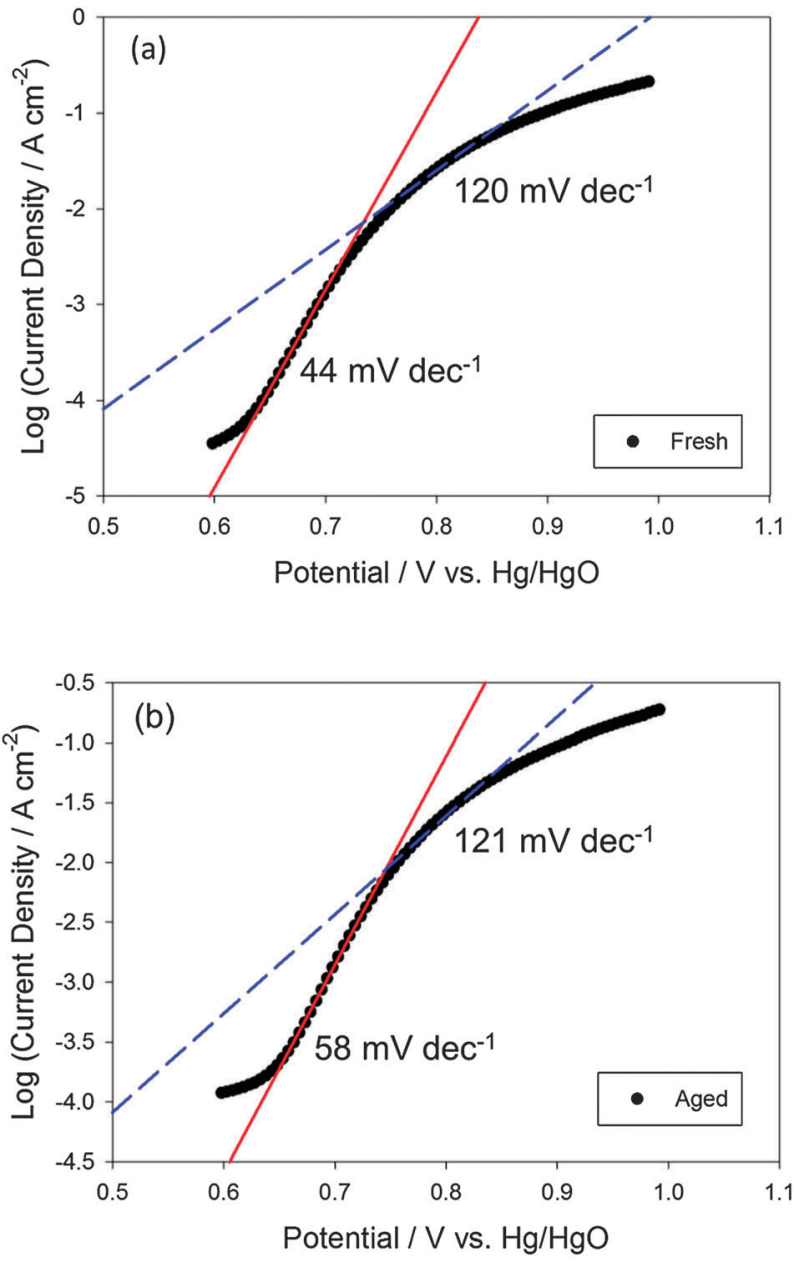

Fig. 6 Steady-state polarisation curves recorded in $5.0 \mathrm{M} \mathrm{NaOH}$ for a hydrous iron oxide film (a) before and (b) after immersing the film for 2 hours in $5.0 \mathrm{M}$ $\mathrm{NaOH}$. The film was grown using 120 growth cycles in $0.1 \mathrm{M} \mathrm{NaOH}$ between $-1.33 \mathrm{~V}$ and $0.75 \mathrm{~V}$ at $400 \mathrm{mV} \mathrm{s}^{-1}$.

properties being exhibited by the hydrous oxide films. With this in mind, the electrochemical impedance response of hydrous iron oxide covered electrodes was recorded over a range of potentials associated with active oxygen evolution. A series of impedance spectra recorded for a Type A and Type B hydrous oxide film, prepared using 120 growth cycles, are presented in the Nyquist and Bode format in Fig. 7. These spectra are representative of the impedance response of the different hydrous iron oxide films as a whole. The raw impedance data was fitted, using a CNLS fitting algorithm, to the equivalent circuit model depicted in Fig. 8 and the simulated data is presented as a continuous line in Fig. 7. The best-fit values of the equivalent circuit elements from the CNLS fitting procedure are listed in Table 1.

In general, the EIS responses of both types of hydrous oxide film were characterised by three relaxation processes. This is particularly clear from the three distinct capacitance peaks, modelled in order of decreasing frequency by the $C_{\mathrm{film}}, C_{\mathrm{dl}}$, and $C_{\phi}$ circuit elements, in the phase angle $v s$. log freq. Bode plots of Fig. 7. Equivalently, three pseudo-semi-circular regions can be discerned at lower potentials in the Nyquist plots of Fig. 7. Recently, Lyons and Brandon ${ }^{37}$ reported a detailed discussion on the significance of the circuit model shown in Fig. 8 for passive oxide covered $\mathrm{Ni}$, Co and Fe electrodes. The $C_{\text {film }} R_{\text {film }}$ loop of the equivalent circuit model is attributed to the dielectric properties and the resistivity of the underlying compact oxide film, respectively. The $C_{\mathrm{dl}}$ element models the doublelayer capacitance, while $R_{\Omega}$ represents the electrolyte resistance. The resistive elements $R_{\mathrm{S}}$ and $R_{\mathrm{p}}$ are related to the kinetics of the interfacial charge transfer reaction. In accordance with the work of Harrington and Conway, ${ }^{38} R_{\mathrm{p}}$ and $R_{\mathrm{s}}$ cannot be interpreted simply as the charge transfer resistances of the electrosorption and electrodesorption steps, respectively, but are each instead attributed to the properties of two or more steps in the overall reaction. Following the assertions of the same authors, $C_{\phi}$ is given the value of a capacitor which in parallel with $R_{\mathrm{S}}$ correctly models the relaxation of the charge associated with a surface intermediate. While it is tempting to interpret $C_{\phi}$ as the steadystate adsorption pseudo-capacitance, ${ }^{39}$ Harrington and Conway ${ }^{38}$ have shown that, in the general case, there is no simple relationship between these two quantities.

One further point regarding the equivalent circuit analysis was the necessity to use constant phase elements in place of pure capacitors. CPEs are commonly used to simulate frequency dispersion in the various capacitive responses of a system. Such frequency dispersion which is evident from the depressed nature of the semicircles in the Nyquist plots in Fig. 7 is believed to arise from surface roughness and inhomogeneity. ${ }^{40}$ The impedance $Z_{\mathrm{CPE}}$ of a capacitive process displaying frequency dispersion is expressed as,

$$
Z_{\mathrm{CPE}}=A(j \omega)^{-\alpha}
$$

where $A=1 / C_{a=1}, C_{a=1}$ is the value of the capacitance in the absence of frequency dispersion and $\alpha$ is an exponent equal to unity for an ideal capacitor and $\alpha \leq 1$ for all other physically reasonable situations. The result of a CNLS fitting of the raw impedance data to a CPE using the Thales SIM program, is an output in the form of optimised values for $C_{\alpha=1}$ and $\alpha$. While the physical significance of the $\alpha$ parameter is uncertain, it is reasonable to conclude that the smaller the value of $\alpha$ the less uniform the electrode surface. Therefore, with increasing surface roughness and dispersion, the magnitude of $\alpha$ will decrease as the classical concept of the double layer capacitance of an ideally smooth uniform electrode/solution interface becomes progressively less applicable. Taking this into consideration, the average $\alpha$ values listed in Table 1 for $C_{\mathrm{dl}}$ and $C_{\phi}$ suggest that the hydrous oxide layer exhibits significant surface roughness, in agreement with the SEM results outlined above (Fig. 2b).

In the present discussion, our primary interest is in the contrasting OER kinetic properties of Type A and Type B hydrous oxide films. Although both types of hydrous oxide film exhibit a similar general EIS response, characterised by three relaxation processes, distinct differences in their responses can also be observed in Fig. 7. This is further illustrated in Fig. 9 where a comparison of the impedance spectra for a Type A and 

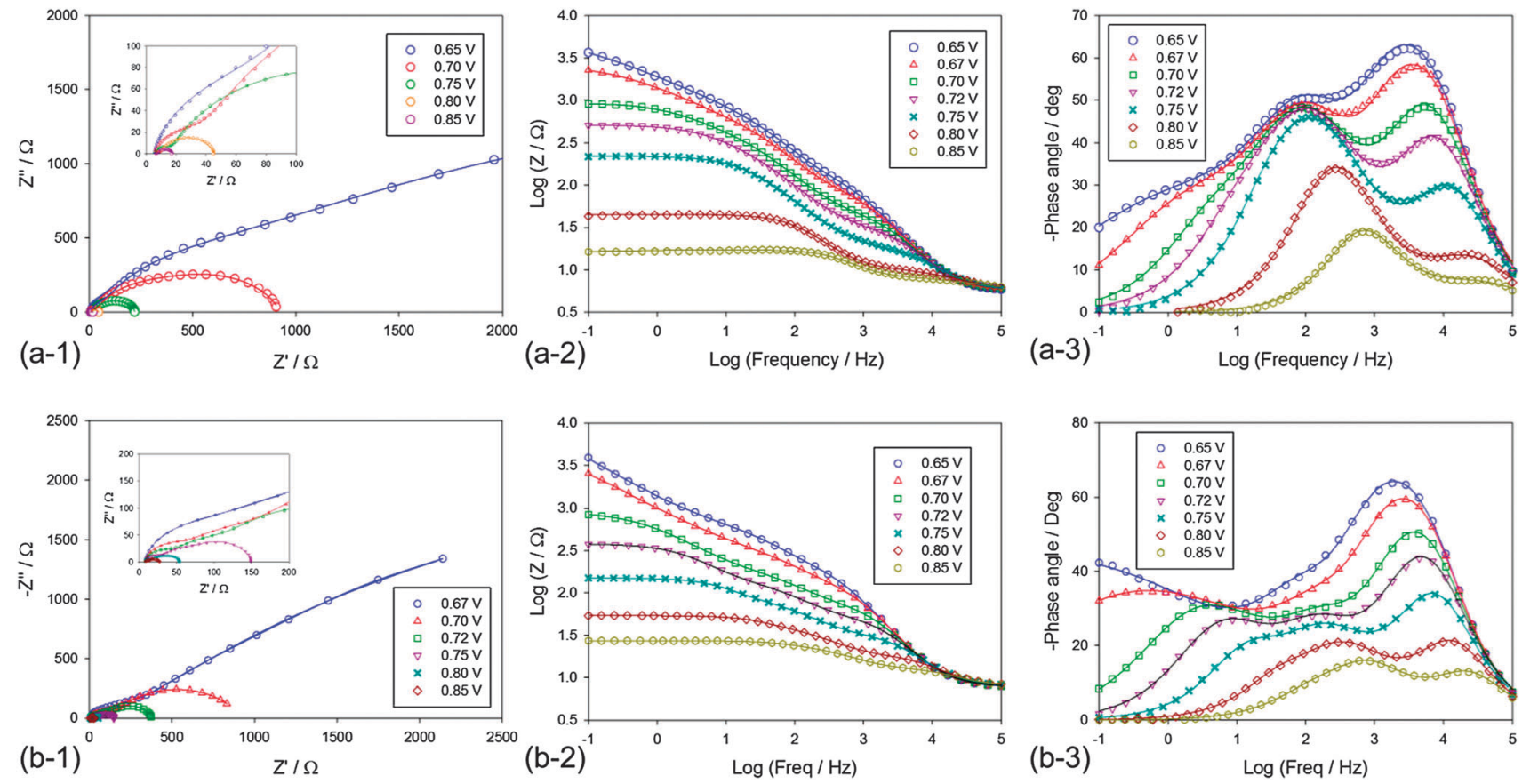

Fig. 7 Electrochemical impedance spectra recorded in $1.0 \mathrm{M} \mathrm{NaOH}$ at a series of potentials associated with active oxygen evolution for (a) Type A and (b) Type B 120 cycled hydrous iron oxide films in the Nyquist (1) and Bode (2-3) format. The experiment data is represented by discrete points and the simulated impedance response is represented by a continuous line. The high frequency region of the Nyquist plot is shown as an inset.

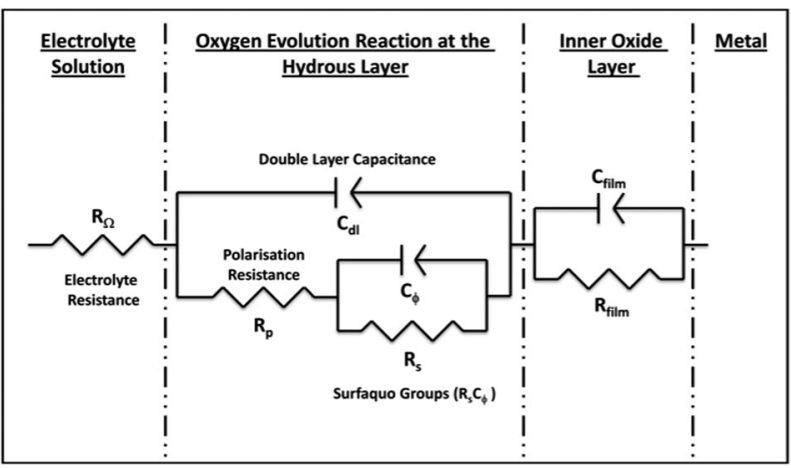

Fig. 8 Equivalent circuit used in the CNLS fitting of the impedance data presented in Fig. 7

Type B film at $0.70 \mathrm{~V}$ is presented in both the Nyquist and Bode format. It is clear from Fig. 9 that the high frequency impedance response is relatively unaffected by the film preparation method, thus supporting our assignment of $C_{\text {film }}$ and $R_{\text {film }}$ as the capacitance and resistance, respectively, of the underlying compact oxide layer. The redox peaks attributed to the compact layer typically show little development with potential cycling and so, the film preparation method should not affect the properties of this layer. Conversely, the impedance responses at low to intermediate frequencies differ quite significantly with preparation method. Given that the impedance response at these frequencies is governed by the Faradaic OER and that it is the outer hydrous layer and not the inner compact layer that will be affected by the growth conditions, this observation confirms our previous assertion that the OER catalytic centres are part of the hydrous layer. Therefore, in order to gain a better understanding of the different kinetic properties of the hydrous oxide films, we now conduct a closer examination of the individual contributions to the overall Faradaic impedance.

Table 1 Optimum fit parameters for the CNLS fitting of the impedance data in Fig. 6 to the equivalent circuit

\begin{tabular}{|c|c|c|c|c|c|c|c|c|c|c|c|c|}
\hline$E / \mathrm{V}$ & \multicolumn{6}{|l|}{ Type A } & \multicolumn{6}{|l|}{ Type B } \\
\hline 0.65 & 16.1 & 69.9 & 44.9 & 347.0 & 13.4 & 13420 & 14.9 & 144.1 & 44.3 & 237.1 & 41.6 & 32080 \\
\hline 0.70 & 15.8 & 25.2 & 76.0 & 338.1 & 304.3 & 286.5 & 15.5 & 46.0 & 54.8 & 99.9 & 185.6 & 785.8 \\
\hline 0.72 & 15.4 & 17.7 & 100.6 & 171.7 & 244.4 & 125.1 & 14.7 & 36.3 & 87.1 & 77.6 & 392.2 & 247.7 \\
\hline 0.75 & 15.1 & 10.0 & 130.8 & 58.4 & 150.0 & 53.7 & 14.2 & 22.3 & 116.1 & 37.3 & 516.5 & 72.8 \\
\hline
\end{tabular}

Note: Mean $\alpha$ values for $C_{\text {film }}(0.95,0.93), C_{\mathrm{dl}}(0.88,0.89)$ and $C_{\phi}(0.78,0.78)$ for Type A and Type B films respectively. The mean $R_{\Omega}$ value was $4.8 \pm 0.2 \Omega$ which is in good agreement with the solution resistance values obtained using chronoamperometry, as outlined above. 

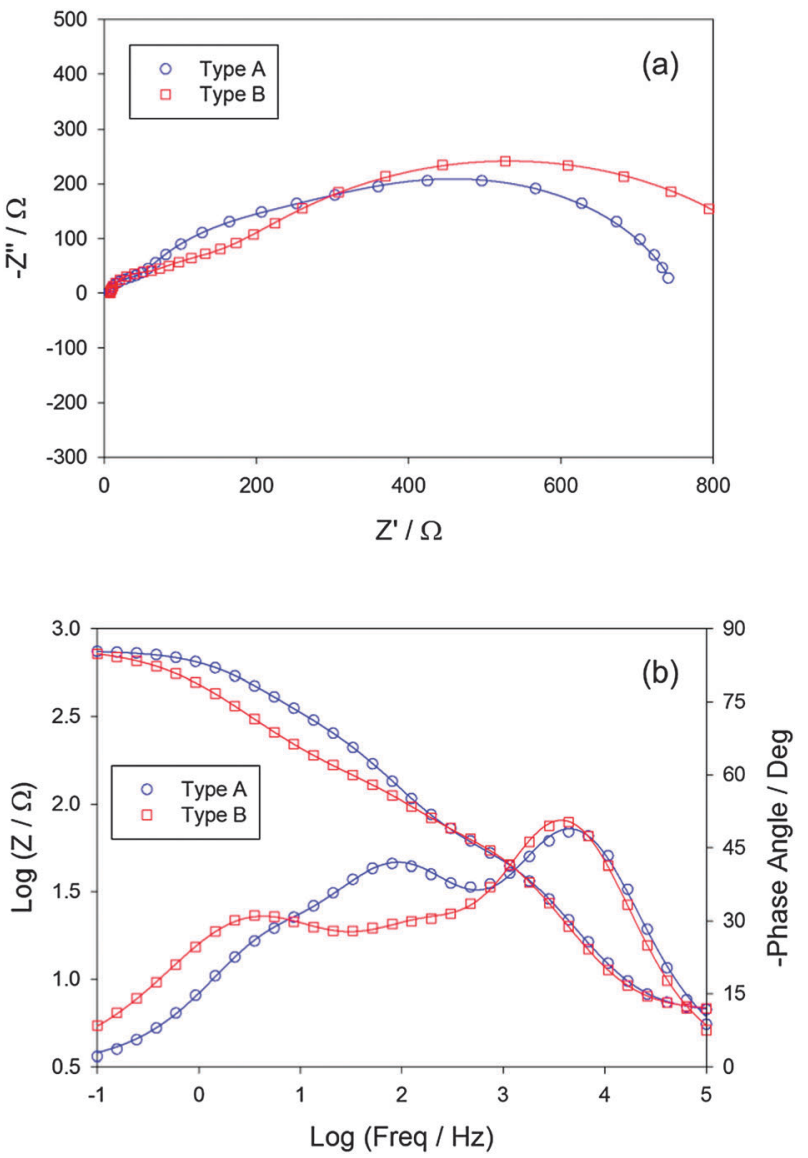

Fig. 9 Electrochemical impedance spectra recorded at $0.70 \mathrm{~V}$ in $1.0 \mathrm{M} \mathrm{NaOH}$ for Type A and Type B hydrous oxide films represented in (a) the Nyquist and (b) the Bode format.

Taking this into consideration, the fitting values obtained for the $C_{\mathrm{d} 1} R_{\mathrm{p}}$ and $C_{\phi} R_{\mathrm{s}}$ loops in the equivalent circuit model are plotted as a function of applied potential in Fig. 10 and 11 respectively. It is clear from Fig. 10a that both films exhibit similar double-layer capacitive behaviour. For ease of discussion the OER steady-state current is also shown. Initially, before the onset of significant oxygen evolution current, the value of $C_{\mathrm{dl}}$ was approximately $44 \mu \mathrm{F} \mathrm{cm} \mathrm{cm}^{-2}$. As an aside, it is important to note that the value obtained here for $C_{\mathrm{dl}}$ using EIS agrees well with the value $c a .47 \mu \mathrm{F} \mathrm{cm}^{-2}$ obtained using chronoamperometry and thus, highlights the accuracy of our fitting procedure and confirms that the circuit shown in Fig. 8 is a good model for our system. Such elevated values of $C_{\mathrm{dl}}$, in comparison with a typical double-layer capacitance, are to be expected given the oxide covered nature of the electrode surface. Indeed the average $\alpha$ value shown in Table 1 for the $C_{\mathrm{dl}}$ element was 0.88 indicating significant roughness of the electrode surface. As the applied potential was increased, the value of $C_{\mathrm{dl}}$ also increased up to an apparent maximum. Interestingly, the increase in the capacitance coincided with the onset of significant oxygen evolution current. Therefore, this variation in the value of $C_{\mathrm{dl}}$ is likely a reflexion of the increasing concentration of charged surface states as the OER progresses.
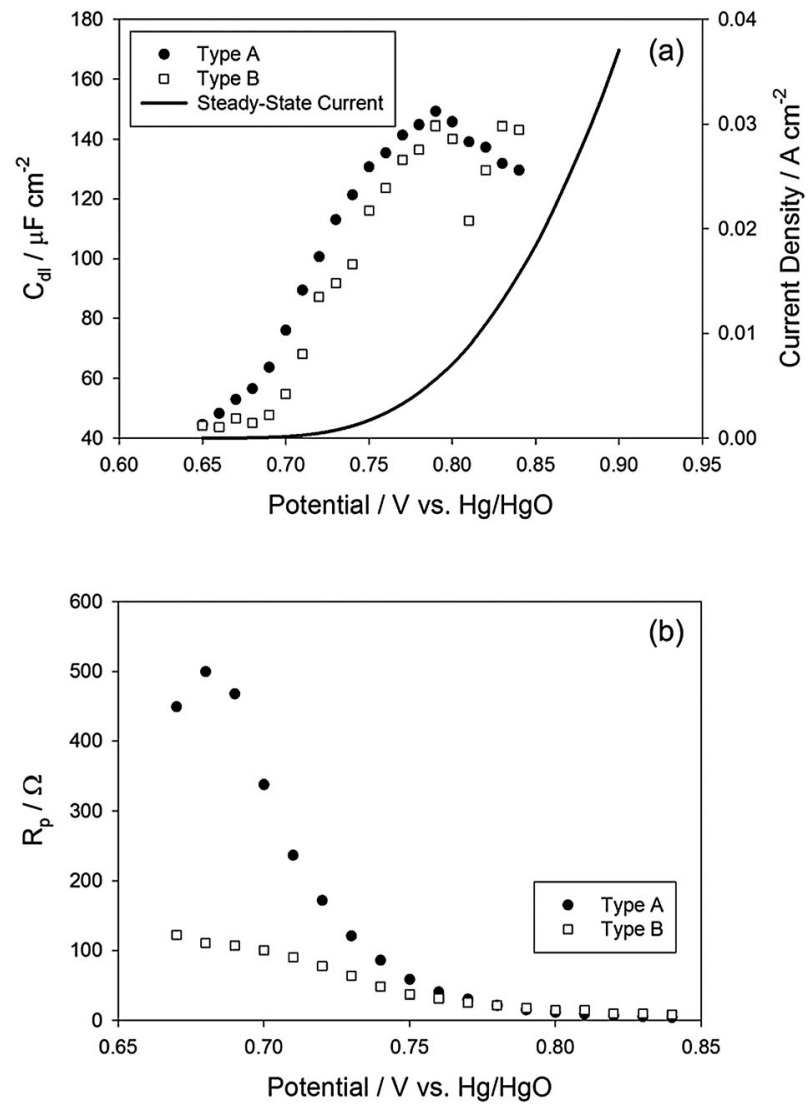

Fig. 10 The optimum fitting values of (a) $C_{\mathrm{dl}}$ and (b) $R_{\mathrm{p}}$ plotted as a function of applied potential for Type A and Type B 120 cycled hydrous oxide films. A typical steady state current profile for a 120 cycled Type A film is also presented in (a) above.

However, the origin of the capacitive maximum is uncertain. That said, Bisquert and coworkers ${ }^{41}$ have observed a similar trend for $\mathrm{IrO}_{2}$ and $\mathrm{IrO}_{2} / \mathrm{Nb}_{2} \mathrm{O}_{5}$ electrodes. The latter authors attributed the observed maximum and subsequent decrease in the capacitance to the strong evolution of gas bubbles at the higher potentials. This could reduce in total the exposed surface area of the electrode thereby influencing its capacitive behaviour.

The polarisation resistance $R_{\mathrm{p}}$ can be viewed as a total charge transfer resistance for the combined steps of the OER. In the theoretical treatment of Harrington and Conway, ${ }^{38}$ the reciprocal resistance $1 / R_{\mathrm{p}}$ was shown to be equal to the sum of similar reciprocal resistances for each of the individual charge transfer steps. Consequently, $R_{\mathrm{p}}$ is related to the overall rate of the OER. The variation of $R_{\mathrm{p}}$ as a function of applied potential is presented in Fig. 10b. As expected for a Faradaic process, the resistance for each film decreases with increasing potential indicating increased electron transfer kinetics. At high potentials, $E \geq 0.76 \mathrm{~V}$, there is little difference in the $R_{\mathrm{p}}$ values obtained for each film. However, at lower potentials the resistances diverge with Type A films displaying significantly greater $R_{\mathrm{p}}$ values than Type B films. Importantly, this observation mirrors the Tafel characteristics associated with these films. Recall that all the hydrous oxide films exhibit $120 \mathrm{mV} \mathrm{dec}^{-1}$ 

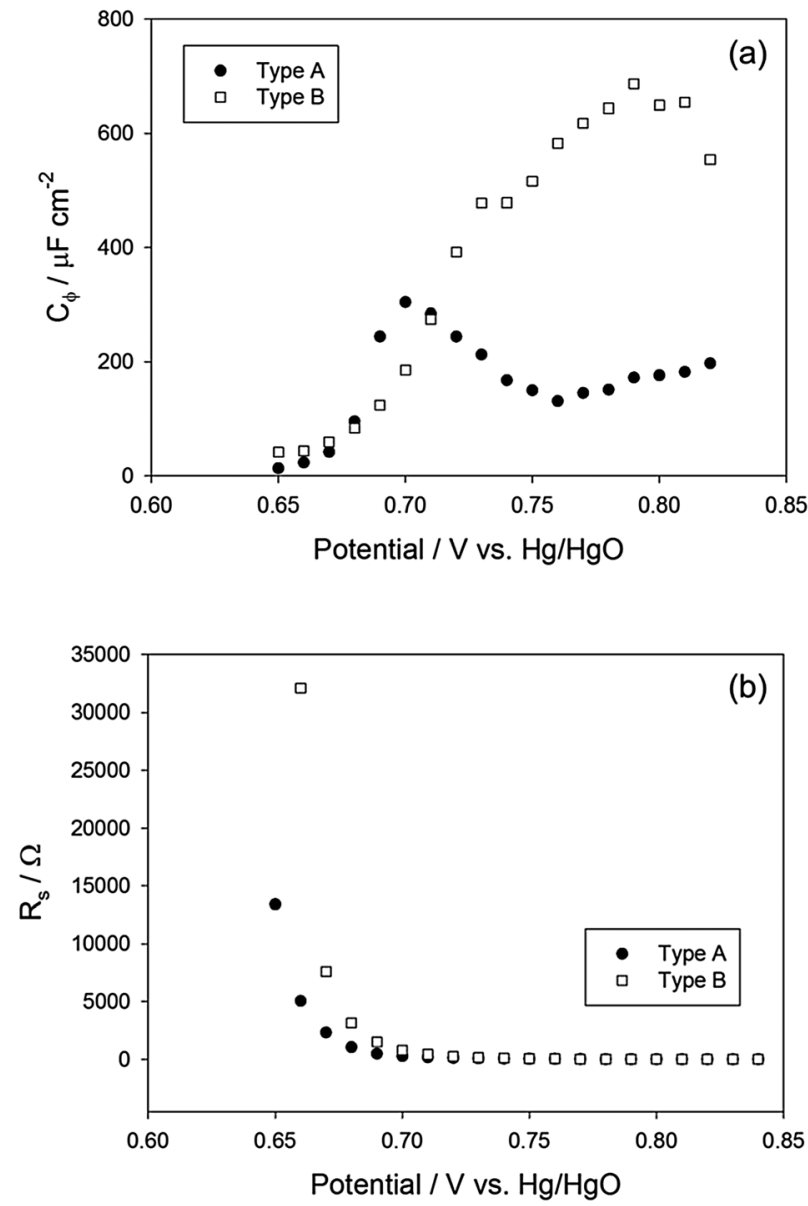

Fig. 11 The optimum fitting values of (a) $C_{\phi}$ and (b) $R_{s}$ plotted as a function of applied potential for Type A and Type B 120 cycled hydrous oxide films.

Tafel slopes at high overpotentials whereas at low overpotentials the Tafel slopes deviate, giving $60 \mathrm{mV} \mathrm{dec}{ }^{-1}$ and $40 \mathrm{mV} \mathrm{dec}{ }^{-1}$ slopes for the Type A and Type B films respectively. In fact, the potential around which the resistances deviate is located in the low to high Tafel slope transition region, as can be observed from Fig. 4 . In this way, the lower $R_{\mathrm{p}}$ values obtained for Type B films at low overpotentials are consistent with the idea that a lower Tafel slope corresponds with improved electrocatalytic properties.

In Fig. 11 the variation of $C_{\phi}$ and $R_{\mathrm{S}}$ with potential can be observed for both types of hydrous oxide film. It has been noted previously that the $C_{\phi} R_{\mathrm{S}}$ loop in the equivalent circuit models the relaxation of charge associated with a surface intermediate. In this sense, $C_{\phi}$ can be related to the changing concentration of charged intermediates as the OER progresses. It is clear from Fig. 11a that $C_{\phi}$ increased with applied potential eventually reaching a maximum for both films. Such a trend might be expected for a capacitance arising from a Faradaic process. However, the magnitude and potential at which these maxima occur differs greatly for each film. The maximum $C_{\phi}$ value is significantly smaller for Type A films and occurs approximately $100 \mathrm{mV}$ less anodic than that for the Type B film. This can also be observed on a more qualitative level from the Bode-phase plots in Fig. 7 where we note that the low frequency capacitance maximum attributed to $C_{\phi}$ is more readily distinguishable for the Type B films. Although the physical reason behind this is unknown, the fact that these two trends are at variance with each other suggests that the $C_{\phi}$ element describes a different charging process for each film. That is, the intermediates involved in the rate determining process are not the same for each type of film, in agreement with the contrasting Tafel behaviour observed for Type A and Type B hydrous oxide films.

In a similar manner, the divergent behaviour of Rs is also reflective of the differing Tafel characteristics of the hydrous oxide films. It can be seen from Fig. $11 \mathrm{~b}$ that the $R_{\mathrm{S}}$ values decrease significantly with applied potential. Moreover, as was the case for $R_{\mathrm{p}}$, these values differ greatly at low potentials. Harrington and Conway ${ }^{38}$ have shown that $R_{\mathrm{S}}$ is related, albeit in a rather complicated fashion, to the rate of production of one or more surface intermediates. In a general way, $R_{\mathrm{S}}$ gives an indication of the ease with which these species can be formed. Thus, as the potential is increased, the intermediate is more readily formed and $R_{\mathrm{S}}$ decreases. Accordingly, it is fitting that $R_{\mathrm{S}}$ diverges for Type A and Type B films at potentials corresponding to the low Tafel region as this is a further illustration of the change in the rate determining step associated with these films.

Finally, we perform a Tafel analysis of the OER impedance data. EIS provides a useful accessory method for the determination of Tafel slopes, especially when combined with dc steady state polarisation data. Obtaining equivalent Tafel slopes using EIS involves the experimental determination of the total Faradaic resistance $R_{\text {far }}$ as a function of applied potential. In the present case, $R_{\mathrm{far}}$ is calculated from the fitting parameters as $R_{\mathrm{far}}=R_{\mathrm{p}}+R_{\mathrm{s}}$. At an oxygen evolution overpotential $\eta$ where simple Tafel behaviour prevails, the current density $i$ is related to $\eta$ via the following expression,

$$
i=i_{0} \exp (2.303 \eta / b)
$$

where $i_{0}$ is the exchange current density for the OER. Taking the derivative of $i$ with respect to $\eta$ gives,

$$
\frac{\mathrm{d} i}{\mathrm{~d} \eta}=\frac{2.303 i}{b} \exp (2.303 \eta / b)
$$

Therefore, noting that $\mathrm{d} i / \mathrm{d} \eta=\mathrm{d} i / \mathrm{d} E=1 / R_{\mathrm{far}}$, and by performing a logarithmic analysis of eqn (6) the following expression is achieved,

$$
\log \left(\frac{1}{R_{\mathrm{far}}}\right)=\frac{E}{b}+\log \left(\frac{2.303 i_{0}}{b}\right)
$$

implying that the inverse slope of a plot of $\log \left(1 / R_{\text {far }}\right)$ against $E$ is equal to the Tafel slope $b$. The plots of $\log \left(1 / R_{\text {far }}\right) v s$. $E$ generated for the 120-cycled Type A and Type B hydrous oxide films are presented in Fig. 12. For ease of comparison, the corresponding dc Tafel plots are also shown. It is apparent that there is satisfactory agreement between the two different methods. Tafel slopes of $c a .60 \mathrm{mV} \mathrm{dec}{ }^{-1}$ and $40 \mathrm{mV} \mathrm{dec}{ }^{-1}$ were observed at low overpotentials for the Type A and Type B films respectively with a Tafel slope of $c a .120 \mathrm{mV} \operatorname{dec}^{-1}$ 

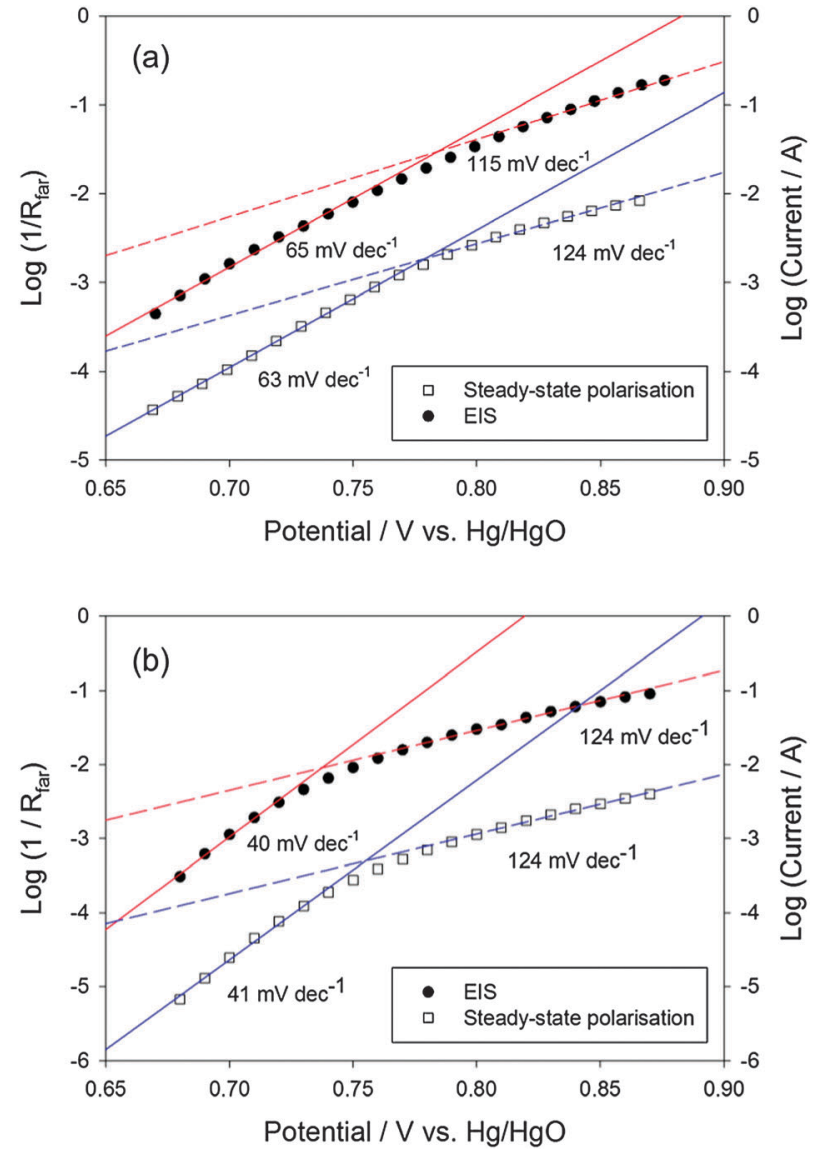

Fig. 12 Tafel plots generated from EIS and steady-state polarisation data recorded in $1.0 \mathrm{M} \mathrm{NaOH}$ for (a) Type A and (b) Type B 120 cycled hydrous oxide films.

uniformly observed at high overpotentials, for both the steady state polarisation data and the impedance data.

\section{Mechanism of oxygen evolution}

In summary, any mechanistic interpretation of the OER at multi-cycled Fe electrodes must be capable of accounting for the variety of kinetic parameters outlined above. To aid in our mechanistic discussion these parameters have been summarised in Table 2. For the purposes of a theoretical analysis we have assumed idealised values for each reaction order and these are shown in parentheses in Table 2.

Table 2 Experimentally determined kinetic parameters for the OER at hydrous iron oxide covered electrodes

\begin{tabular}{llllll}
\hline \multirow{2}{*}{$\begin{array}{lllll}\text { Growth medium } / \\
\text { mol dm }^{-3}\end{array}$} & \multicolumn{2}{l}{ Low Tafel region } & & \multicolumn{2}{l}{ High Tafel region } \\
\cline { 2 - 3 } & $b / \mathrm{mV} \mathrm{dec}^{-1}$ & $m_{\mathrm{OH}^{-}}$ & & $b / \mathrm{mV} \mathrm{dec}^{-1}$ & $m_{\mathrm{OH}^{-}}$ \\
\hline 0.1 & $40(2 P / 3)$ & $0.98(1.0)$ & & $120(2 P)$ & $0.62(0.5)$ \\
0.5 & $40(2 P / 3)$ & $1.33(1.0)$ & & $120(2 P)$ & $0.95(1.0)$ \\
1.0 & $60(P)$ & $1.01(1.0)$ & $120(2 P)$ & $0.94(1.0)$ \\
5.0 & $60(P)$ & $0.92(1.0)$ & $120(2 P)$ & $0.77(1.0)$
\end{tabular}

Note: Theoretical diagnostic values are given in parentheses where $P=$ $2.303 R T / F$. Growth medium was aqueous $\mathrm{NaOH}$.
Our proposed mechanism is represented schematically in Scheme 1 and can also be described by the following reaction sequence,

$$
\begin{aligned}
\mathrm{SOH}_{2}+\mathrm{OH}^{-} & \rightarrow \mathrm{SOH}^{-}+\mathrm{H}_{2} \mathrm{O} \\
\mathrm{SOH}^{-} & \rightarrow \mathrm{SOH}+e^{-} \\
\mathrm{SOH}+\mathrm{OH}^{-} & \rightarrow \mathrm{SO}^{-}+\mathrm{H}_{2} \mathrm{O} \\
\mathrm{SO}^{-} & \rightarrow \mathrm{SO}+e^{-} \\
\mathrm{SO}+\mathrm{OH}^{-} & \rightarrow \mathrm{SOOH}+e^{-} \\
\mathrm{SOOH}+\mathrm{OH}^{-} & \rightarrow \mathrm{SO}_{2}+\mathrm{H}_{2} \mathrm{O}+e^{-} \\
\mathrm{SO}_{2}+\mathrm{OH}^{-} & \rightarrow \mathrm{SOH}^{-}+\mathrm{O}_{2}
\end{aligned}
$$

where $\mathrm{S}$ represents a surfaquo group attached to the hydrous oxide surface by bridging oxygen ligands. Note that octahedrally co-ordinated oxy-iron surfaquo groups are identified as the catalytically active species and are located within the hydrous layer. This mechanism takes advantage of the fact that the dispersed hydrous layer contains considerable quantities of water molecules which facilitate hydroxide ion discharge at the metal catalytic site. In this way our mechanistic thinking is guided by the earlier work of Kobussen and Broers, ${ }^{23}$ but also takes into account recent developments in DFT calculations ${ }^{26,42}$ and homogeneous OER catalysis. ${ }^{29}$

We now conduct a comprehensive kinetic analysis of the mechanism outlined in Scheme 1. First, we note that the first step in the reaction sequence occurs rapidly and need not be included in the steady-state kinetic analysis. Therefore, if we assume that the step outlined in eqn (10) is rate determining then the net reaction flux is given by,

$$
f_{\Sigma}=i / 4 F A=k_{2} a_{\mathrm{OH}^{-}} \Gamma_{\mathrm{SOH}}
$$

In the latter expression, $k_{2}$ is the chemical rate constant for the step outlined in eqn (10), $a_{\mathrm{OH}^{-}}$represents the activity of the hydroxide ion and $\Gamma$ denotes the surface coverage. We use the quasi steadystate approximation for the surface coverage of $\mathrm{SOH}$ to get,

$$
\frac{\mathrm{d} \Gamma_{\mathrm{SOH}}}{\mathrm{d} t}=k_{1}^{\prime} \Gamma_{\mathrm{SOH}^{-}}-k_{-1}^{\prime} \Gamma_{\mathrm{SOH}}-k_{2} \Gamma_{\mathrm{SOH}} a_{\mathrm{OH}^{-}} \cong 0
$$

where $k_{1}^{\prime}$ and $k_{-1}^{\prime}$ are the heterogeneous electrochemical rate constants for the forward and reverse reactions in eqn (9). We may readily solve eqn (16) to obtain an expression for the surface coverage,

$$
\Gamma_{\mathrm{SOH}} \cong k_{1}^{\prime} \Gamma_{\mathrm{SOH}^{-}} /\left(k_{-1}^{\prime}+k_{2} a_{\mathrm{OH}^{-}}\right)
$$

Hence the net flux is given by,

$$
f_{\Sigma} \cong \frac{k_{2} k_{1}^{\prime} a_{\mathrm{OH}^{-}} \Gamma_{\mathrm{SOH}^{-}}}{k_{-1}^{\prime}+k_{2} a_{\mathrm{OH}^{-}}}
$$

In the latter expression the primed quantities represent heterogeneous electrochemical rate constants whose potential dependence is assumed to be given by the Butler-Volmer rate equation,

$$
k_{n}^{\prime}=k_{n}^{0} \exp \left(\frac{\beta F \eta}{R T}\right), k_{-n}^{\prime}=k_{-n}^{0} \exp \left(\frac{-(1-\beta) F \eta}{R T}\right)
$$




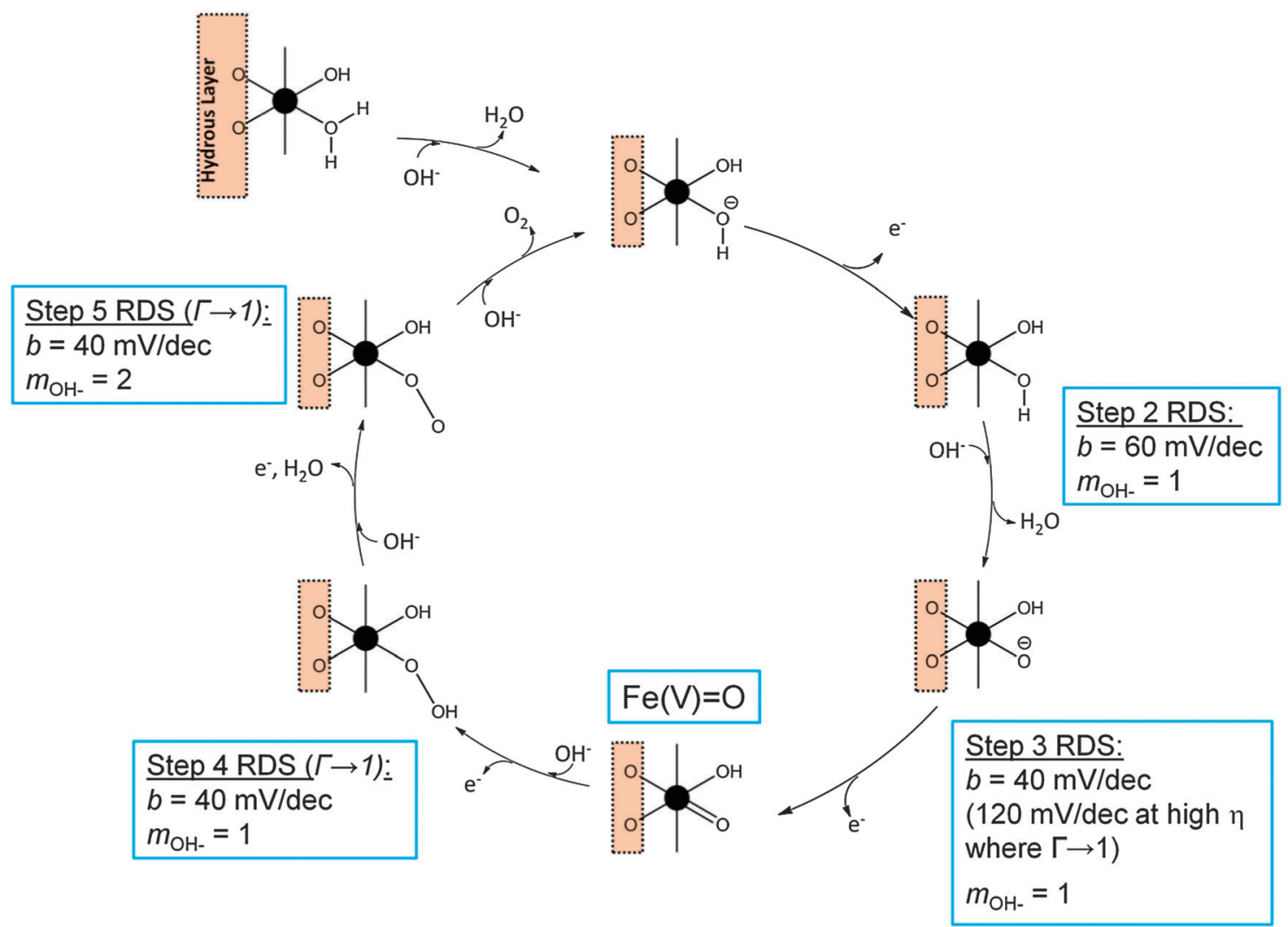

Scheme 1 Mechanism for the OER involving octahedrally coordinated Fe oxyhydroxide surfaquo group.

where $\eta$ denotes the overpotential and $\beta$ is the symmetry factor. In contrast the chemical rate constant is given by its standard value and there is no potential dependence,

$$
k_{n}=k_{n}^{0}
$$

Hence the net flux is given by,

$$
f_{\Sigma} \cong \frac{k_{2}^{0} a_{\mathrm{OH}^{-}} \Gamma_{\mathrm{SOH}^{-}} k_{1}^{0} \exp [\beta F \eta / R T]}{k_{-1}^{0} \exp [-(1-\beta) F \eta / R T]+k_{2}^{0} a_{\mathrm{OH}^{-}}}
$$

Now if the step outlined in eqn (10) is rate determining then we can safely assume that $k_{2}^{0}<k_{-1}^{0}$ and so eqn (21) reduces to,

$$
f_{\Sigma} \cong k_{2}^{0} \Gamma_{\mathrm{SOH}^{-}} a_{\mathrm{OH}^{-}}\left(k_{1}^{0} / k_{-1}^{0}\right) \exp [F \eta / R T]
$$

This expression can be readily shown to predict a reaction order of unity with respect to hydroxide ion activity and a Tafel slope at $298 \mathrm{~K}$ of $c a .60 \mathrm{mV} \mathrm{dec}^{-1}(b=2.303(R T / F))$.

However, if the subsequent step outlined in eqn (11) becomes rate limiting we can write that,

$$
f_{\Sigma} \cong k_{3}^{\prime} \Gamma_{\mathrm{SO}^{-}}
$$

Again applying the quasi steady-state approximation we can show that,

$$
\frac{\mathrm{d} \Gamma_{\mathrm{SO}^{-}}}{\mathrm{d} t}=k_{2} \Gamma_{\mathrm{SOH}} a_{\mathrm{OH}^{-}}-k_{-2} a_{\mathrm{H}_{2} \mathrm{O}} \Gamma_{\mathrm{SO}^{-}}-k_{3}^{\prime} \Gamma_{\mathrm{SO}^{-}} \cong 0
$$

where $k_{-2}$ is the chemical rate constant for the reverse reaction in eqn (10) and $k_{3}^{\prime}$ is the heterogeneous electrochemical rate constant for the reaction in eqn (11). Solving for the surfaquo group coverage we obtain,

$$
\Gamma_{\mathrm{SO}^{-}} \cong k_{2}^{0} \Gamma_{\mathrm{SOH}} a_{\mathrm{OH}^{-}-} /\left(k_{-2}^{0} a_{\mathrm{H}_{2} \mathrm{O}}+k_{3}^{0} \exp [\beta F \eta / R T]\right)
$$

Hence the net reaction flux is given by,

$$
f_{\Sigma} \cong \frac{k_{2}^{0} k_{3}^{0} a_{\mathrm{OH}^{-}} \Gamma_{\mathrm{SOH}} \exp [\beta F \eta / R T]}{k_{-2}^{0} a_{\mathrm{H}_{2} \mathrm{O}}+k_{3}^{0} \exp [\beta F \eta / R T]}
$$

Now substituting for $\Gamma_{\mathrm{SOH}}$ using eqn (17) we can obtain,

$$
f_{\Sigma} \cong k_{3}^{0}\left(\frac{k_{1}^{0} k_{2}^{0}}{k_{-1}^{0} k_{-2}^{0}}\right) a_{\mathrm{H}_{2} \mathrm{O}}^{-1} a_{\mathrm{OH}^{-}} \Gamma_{\mathrm{SOH}^{-}} \exp [(1+\beta) F \eta / R T]
$$

Hence, when the electrochemical oxo generation step eqn (11) is rate limiting the flux expression presented in eqn (27) predicts that a reaction order of unity with respect to hydroxide ion activity and a Tafel slope of $c a .40 \mathrm{mV} \mathrm{dec}{ }^{-1}$ at $298 \mathrm{~K}$ $(b=2.303(2 R T / 3 F))$ will be observed assuming that $\beta=\frac{1}{2}$.

Alternatively, at high overpotentials it is reasonable to assume that $\Gamma_{\mathrm{SOH}} \cong 1$ and also $k_{-2}^{0} \gg k_{3}^{0}$. Thus, eqn (26) reduces to,

$$
f_{\Sigma} \cong k_{3}^{0} a_{\mathrm{H}_{2} \mathrm{O}}^{-1}\left(k_{2}^{0} / k_{-2}^{0}\right) a_{\mathrm{OH}^{-}} \exp [\beta F \eta / R T]
$$

Hence, when the electrochemical oxo generation step eqn (11) is rate limiting at high overpotentials the flux expression presented in eqn (28) predicts that a reaction order of unity with respect to hydroxide ion activity and a Tafel slope of $c a .120 \mathrm{mV} \mathrm{dec}^{-1}$ at $298 \mathrm{~K}(b=2.303(2 R T / F))$ will be observed, 
again assuming that $\beta=\frac{1}{2}$. Furthermore, using a similar approach it can be shown that our mechanism predicts a Tafel slope of $c a .40 \mathrm{mV} \mathrm{dec}{ }^{-1}$ at $298 \mathrm{~K}(b=2.303(2 R T / 3 F))$ with corresponding reaction orders of unity and 2 , respectively, if the formation of the metal peroxide $\mathrm{SOOH}$ or the metal peroxo SOO species are assumed to be rate determining. Therefore, it is gratifying to note that our current mechanism is in excellent agreement with the available kinetic data. That said, further analysis is required to fully account for the kinetic parameters observed at high overpotentials for the hydrous oxide films prepared in $0.1 \mathrm{~mol} \mathrm{dm}^{-3} \mathrm{NaOH}$.

In view of the above kinetic analysis, we wish to highlight here a number of important features of our current mechanism. Firstly, it is important to note that our proposed catalytic cycle for the OER outlined in Scheme 1 is analogous to those depicted for various homogeneous catalyst systems. ${ }^{29}$ This is not unexpected given the very dispersed and somewhat tenuous nature of the catalytically active hydrous oxide layer. A common feature of these reaction schemes is that the initial catalytic step involves the deprotonation of a metal coordinated water molecule. However, in the strongly alkaline conditions used in this system it is likely that a significant proportion of these coordinated water molecules will already be deprotonated. The $\mathrm{p} K_{\mathrm{a}}$ value for a water molecule coordinated to a highly charged metal atom is generally in the range $\mathrm{p} K_{\mathrm{a}} 5-9 .{ }^{43}$ In light of this, it is more reasonable to assume that the initial deprotonation step is facile and will occur outside of the catalytic cycle. Hence, the initial deprotonation step is depicted as a pre-step in Scheme 1 and the OER catalytic cycle begins with the resultant coordinated $\mathrm{OH}^{-}$ion which we label $\mathrm{SOH}^{-}$.

Secondly, it is clear that one of the key steps in our proposed mechanism involves the formation of a surface bound metal oxo SO species. In Scheme 1 above this species is depicted as $\mathrm{M}=\mathrm{O}$ suggesting an $\mathrm{M}(\mathrm{v})$ metal centre. However, this species could also be represented as a metal oxyl moiety $\mathrm{M}(\mathrm{Iv})-\mathrm{O}^{\bullet}$. In actual fact, the degree of radical character has been shown to depend on the length of the metal oxo bond with $\mathrm{M}(\mathrm{v})=\mathrm{O}$ being more stable for shorter bond lengths. ${ }^{29 a, 44}$ In the case of $\mathrm{Fe}$, it is likely that the metal oxo species involves an $\mathrm{Fe}(\mathrm{v})$ metal centre. Indeed, a recent variable temperature mass spectrometry investigation has identified an $\mathrm{Fe}(\mathrm{v})$ oxo species as the catalytic centre in a biomimetric non-heme Fe complex. ${ }^{45}$

Finally, we note that the formation of metal oxide $\mathrm{SO}^{-}$ eqn (10), metal oxo SO eqn (11) and metal peroxide $\mathrm{SOOH}$ eqn (12) species have been designated as possible intermediates in Scheme 1. To date, atomic-scale insight into the OER has proven difficult due to the lack of significant spectroscopic evidence of intermediates. However, recent surface-enhanced Raman spectroscopic (SERS) studies provide convincing evidence for $\mathrm{SOOH}$ intermediates on $\mathrm{Au}, \mathrm{Ni}$ and Co substrates. ${ }^{15 a, 46}$ Specifically, Bell and coworkers ${ }^{46 a}$ found that a characteristic $v(\mathrm{O}-\mathrm{O})$ band of quite low intensity at $815-830 \mathrm{~cm}^{-1}$ could only be observed for a Au substrate at potentials associated with active oxygen evolution. Indeed, the low intensity of the $v(\mathrm{O}-\mathrm{O})$ band in this study highlights the difficulty in obtaining direct experimental evidence for OER intermediates. On the other hand, Muckermann and coworkers ${ }^{42}$ propose, based on DFT calculations, that for a GaN/ZnO surface with high coverage of adsorbed $\mathrm{OH}^{-}$ions the intermediate associated with the highest energy is an oxide radical. Similarly, Rossmeisl et al. ${ }^{26}$ performed DFT studies on the OER at $\mathrm{RuO}_{2}$ surfaces. They too found that for a surface saturated with adsorbed $\mathrm{OH}$, the highest energy intermediate was a surface oxygen species, in this case an oxo species. Furthermore, the latter authors assigned the highest energy state to a peroxide intermediate when the surface was saturated with adsorbed oxo rather than hydroxide species. Therefore, considering these studies, the present mechanistic interpretation brings together a number of strands in the current understanding of the OER at metal oxide electrodes, and reflects current thinking in the allied field of water oxidation in homogeneous catalytic systems via transition metal complexes.

\section{Conclusions}

In conclusion, we have described the growth of hydrous iron oxyhydroxide films on iron substrates in aqueous base and examined the kinetics of active oxygen evolution at these electrodes. Steady-state Tafel plots and electrochemical impedance spectroscopy have been shown to complement each other to provide an effective kinetic analysis of the OER at multicycled iron electrodes. The hydrous oxide films are easy to prepare and bestow excellent electrocatalytic properties on the parent metal. Moreover, the acid/base behavior of the anodically prepared films is an important factor to take into account when considering the mechanism of oxygen evolution.

A novel mechanism involving the active participation of iron oxyhydroxide surfaquo groups has been developed. This mechanism, which is in excellent agreement with experimental data, is inspired by the classic work of Kobussen and Broers ${ }^{23}$ while also resonating with more recent work concerning various oxygen evolving molecular inorganic transition metal complexes. ${ }^{29,44}$ Furthermore, with support from recent spectroscopic and DFT data, iron oxide, oxo and peroxide species are proposed as important intermediates in the oxygen evolution reaction under electrochemical conditions. In agreement with the thoughts of Dau et al. ${ }^{25 a}$ we consider the microdispersed layer as an elongated intermingled array of octahedrally coordinated Fe surfaquo groups. Importantly, the structure of the surfaquo groups mirrors that of homogeneous molecular catalysts. Thus, in our work we have integrated the allied fields of heterogeneous and homogeneous OER catalysis. Indeed, we can conclude that the chemistry of the surfaquo group determines the chemistry of the OER catalytic cycle.

\section{Acknowledgements}

This publication has emanated in part from research conducted with the financial support of Science Foundation Ireland (SFI) under grant number SFI/10/IN.1/I2969. We also wish to thank the Advanced Microscopy Laboratory (AML) in 
the Centre for Research on Adaptive Nanostructures and Nanodevices (CRANN) at Trinity College Dublin for their help with the SEM analysis.

\section{Notes and references}

1 K. Zeng and D. Zhang, Prog. Energy Combust. Sci., 2010, 36, 307.

2 H. Tributsch, Int. J. Hydrogen Energy, 2008, 33, 5911.

3 G. W. Crabtree, M. S. Dresselhaus and M. V. Buchanan, Phys. Today, 2004, 57, 39.

4 J. Ohi, J. Mater. Res., 2005, 20, 3180.

5 D. E. Hall, J. Electrochem. Soc., 1983, 130, 317.

6 A. Michas, F. Andolfatto, M. E. G. Lyons and R. Durand, Key Eng. Mater., 1992, 72-74, 535.

7 K. Kinoshita, Electrochemical Oxygen Technology, Wiley, New York, 1992.

8 M. E. G. Lyons and M. P. Brandon, Int. J. Electrochem. Sci., 2008, 3, 1386.

9 M. E. G. Lyons and M. P. Brandon, Int. J. Electrochem. Sci., 2008, 3, 1425.

10 M. E. G. Lyons and M. P. Brandon, Int. J. Electrochem. Sci., 2008, 3, 1463.

11 M. E. G. Lyons, R. L. Doyle and M. P. Brandon, Phys. Chem. Chem. Phys., 2011, 13, 21530.

12 M. E. G. Lyons, L. Russell, M. O’Brien, R. L. Doyle, I. Godwin and M. P. Brandon, Int. J. Electrochem. Sci., 2012, 7, 2710.

13 (a) T. Kessler, J. R. Vilche, M. Ebert, K. Jüttner and W. J. Lorenz, Chem. Eng. Technol., 1991, 14, 263; (b) K. K. Lian, D. W. Kirk and S. J. Thorpe, J. Electrochem. Soc., 1995, 142, 3704; (c) A. M. Fundo and L. M. Abrantes, Russ. J. Electrochem., 2006, 42, 1291.

14 (a) S. I. Cordorba, R. B. Carbonio, M. Lopez Teijelo and V. A. Macagno, Electrochim. Acta, 1987, 32, 749; (b) Y. Zhang, X. Cao, H. Yuan, W. Zhang and Z. Zhou, Int. J. Hydrogen Energy, 1999, 24, 529; (c) X. Wang, H. Luo, D. R. Zhou, H. Yang, P. J. Sebastian and S. A. Gamboa, Int. J. Hydrogen Energy, 2004, 29, 967.

15 (a) B. S. Yeo and A. T. Bell, J. Am. Chem. Soc., 2011, 133, 5587; (b) E. B. Castro, C. A. Gervasi and J. R. Vilche, J. Appl. Electrochem., 1998, 28, 835.

16 M. S. El-Deab, M. I. Awad, A. M. Mohammad and T. Ohsaka, Electrochem. Commun., 2007, 9, 2082.

17 (a) C. R. Davidson, G. Kissel and S. Srinivasan, J. Electroanal. Chem., 1982, 132, 129; (b) S. K. Tiwari, S. Samuel, R. N. Singh, G. Poillerat, J. F. Koenig and P. Chartiers, Int. J. Hydrogen Energy, 1995, 20, 9; (c) C. Bocca, A. Barbucci, M. Delucchi and G. Cerisola, Int. J. Hydrogen Energy, 1999, 24, 21.

18 (a) C. Iwakura, A. Honji and H. Tamura, Electrochim. Acta, 1981, 26, 1319; (b) P. Rasiyah and A. C. C. Tseung, J. Electrochem. Soc., 1983, 130, 365; (c) S. Palmas, F. Ferrara, A. Vacca, M. Mascia and A. M. Polcaro, Electrochim. Acta, 2007, 53, 400.

19 (a) J. P Singh, N. K. Singh and R. N. Singh, Int. J. Hydrogen Energy, 1999, 24, 433; (b) R. N. Singh, J. P. Singh, B. Lal, M. J. K. Thomas and S. Bera, Electrochim. Acta, 2006, 51, 5515.
20 (a) J. O'M. Bockris and T. Otagawa, J. Phys. Chem., 1983, 87, 2960; (b) Y. Matsumoto, S. Yamada, T. Hishida and E. Sato, J. Electrochem. Soc., 1980, 127, 2360; (c) C. Bocca, G. Cerisola, E. Magnone and A. Barbucci, Int. J. Hydrogen Energy, 1999, 24, 699; (d) R. N. Singh and B. Lal, Int. J. Hydrogen Energy, 2002, 27, 45.

21 B. Klahr, S. Gimenez, F. Fabregat-Santiago, T. Hamann and J. Bisquert, J. Am. Chem. Soc., 2012, 134, 4294.

22 A. I. Krasil'shchikov, Zh. Fiz. Khim., 1963, 37, 531.

23 (a) A. G. C. Kobussen and G. H. J. Broers, J. Electroanal. Chem., 1981, 126, 221; (b) H. Willems, A. G. C. Kobussen, J. H. W. De Wit and G. H. J. Broers, J. Electroanal. Chem., 1984, 170, 227.

24 W. O'Grady, C. Iwakura, J. Huang and E. Yeager, in Proceedings of the Symposium on Electrocatalysis, ed. M. W. Breiter, The Electrochemical Society Inc., Pennington, NJ, 1974, pp. 286.

25 (a) H. Dau, C. Limberg, T. Reier, M. Risch, S. Roggan and P. Strasser, ChemCatChem, 2010, 2, 724; (b) S. Marinia, P. Salvi, P. Nelli, R. Pesentia, M. Villa, M. Berrettoni, G. Zangaric and Y. Kiros, Electrochim. Acta, 2012, 82, 384 .

26 J. Rossmeisl, Z.-W. Qu, H. Zhu, G.-J. Kroes and J. K. Nørskov, J. Electroanal. Chem., 2007, 607, 83.

27 J. Suntivich, K. J. May, H. Gasteiger, J. B. Goodenough and Y. Shao-Horn, Science, 2011, 334, 1383.

28 R. Subbaraman, D. Tripkovic, K.-C. Chang, D. Strmcnik, A. P. Paulikas, P. Hirunsit, M. Chan, J. Greeley, V. Stamenkovic and N. M. Markovic, Nat. Mater., 2012, 11, 550 .

29 (a) M. Busch, E. Ahlberg and I. Panas, Phys. Chem. Chem. Phys., 2011, 13, 15069; (b) L.-P. Wang, Q. Wu and T. Van Voorhis, Inorg. Chem., 2010, 49, 4543; (c) L. Duan, F. Bozoglian, S. Mandal, B. Stewart, T. Privalov, A. Llobet and L. Sun, Nature, 2012, 4, 418.

30 M. E. G. Lyons and M. P. Brandon, Phys. Chem. Chem. Phys., 2009, 11, 2203.

31 M. E. G. Lyons and L. D. Burke, J. Electroanal. Chem., 1984, $170,377$.

32 (a) T. E. Pou, O. J. Murphy, V. Young, J. O'M. Bockris and L. L. Tongson, J. Electroanal. Chem., 1984, 131, 1243; (b) V. Jovancicevic, R. C. Kainthla, Z. Tang, B. Yang and J. O'M. Bockris, Langmuir, 1987, 3, 388.

33 W. E. O'Grady, J. Electrochem. Soc., 1980, 127, 555.

34 L. D. Burke and E. J. M. O'Sullivan, J. Electroanal. Chem., 1981, 117, 155.

35 M. E. G. Lyons and R. L. Doyle, Int. J. Electrochem. Sci., 2012, 7, 9488.

36 R. A. Robinson and R. H. Stokes, Electrolyte Solutions, Butterworth \& Co. Ltd., London, 1965, pp. 492.

37 M. E. G. Lyons and M. P. Brandon, J. Electroanal. Chem., 2009, 631, 62.

38 D. A. Harrington and B. E. Conway, Electrochim. Acta, 1987, 32, 1703.

39 B. E. Conway and E. Gileadi, Trans. Faraday Soc., 1962, 58, 2493. 
40 B. E. Conway, in Impedance Spectroscopy -Theory, Experiment, and Applications, ed. E. Barsoukov and J. R. Macdonald, J. Wiley \& Sons, 2nd edn, 2005, pp. 469-497.

41 A. J. Terezo, J. Bisquert, E. C. Pereira and G. GarciaBelmonte, J. Electroanal. Chem., 2001, 508, 59.

42 X. Shen, Y. A. Small, J. Wang, P. B. Allen, M. V. FernandezSerra, M. S. Hybertsen and J. T. Muckerman, J. Phys. Chem. C, 2010, 114, 13695.
43 G. A. Lawrence, Introduction to Coordination Chemistry, J. Wiley \& Sons, West Sussex, 2010, pp. 199.

44 P. E. M. Siegbann and R. H. Crabtree, J. Am. Chem. Soc., 1999, 121, 117.

45 A. R. McDonald and L. Que, Nature, 2011, 3, 761.

46 (a) B. S. Yeo, S. L. Klaus, P. N. Ross, R. A. Mathies and A. T. Bell, ChemPhysChem, 2010, 11, 1854; (b) B. S. Yeo and A. T. Bell, J. Phys. Chem. C, 2012, 116, 8394. 